\title{
The Issues of Statistical Observation of Labor Force Migration
}

\author{
Mukaddas Umarova (Tashkent State University of Economics, Uzbekistan)
}

\begin{abstract}
Objective statistical information allows to provide the effective performance of government acts on migration, evaluate their consequence and results, and compare migration follows in different regions of the world. In international standards there is no unique comments and recommendations on information sources of statistical indicators about employment, unemployment, economic activeness and territorial movement of population. Observation of households is the most flexible method of collection of all information.
\end{abstract}

\section{Introduction}

The study of the international labor market requires complete and clear data on employment, unemployment, economic activity and regional migration opportunities of the population of a country.

The statistical procedures of the economically active population at each state level are used to describe international labor reserves. Sources of information about this can be grouped as follows:

1) The list of population and household researches;

2) Registration of enterprises and selection of enterprises;

3) Various types of administrative accounts, such as employment promotion centers, unemployment insurance agencies, social security agencies, salaries of civil servants and lists of enterprises and organizations.

These various sources may vary depending on the types and levels of information contained in them, the scope and description, the concepts and their definitions, units of measurement, the value of the work, the quality and effectiveness of the data, etc. Some source variations are based on the nature and nature of the sources, and each of them has certain advantages and disadvantages. For example, if information in one source fully meets the needs of a user group, another group may prefer another resource. Therefore, it is advisable to consider different sources, and not mutually exclude each other. Making a list of key people can provide complete information about the state of the labor market. There may be different questionnaires in the registry in different countries, but most of them contain a full set of indicators for the use of labor and migration opportunities.

There are no clear guidelines and recommendations for some data sources on statistical indicators of employment, unemployment, economic activity and territorial migration of populations in international standards. Although, these international standards are theoretically viable for different sources of information, in practice they are more suitable for data collection based on household surveys. In fact, some of the criteria provided by international standards can only be used for conducting household surveys that are specifically considered rather than from other sources.

Household surveys are the most flexible tool for collecting information. During the transfer process, various aspects can be explored. For example, it may be useful to compare employment information related to other issues of the same study, including answers to questions about income and knowledge. The content, description and details of the questions can be easily adapted to the requirements for information on the economic activity of the population. This flexibility is especially useful for meeting the needs of different consumers and maintaining international comparisons. Internal resettlement ensures that virtually all residents of the state, all sectors of economic activity, all sectors of the economy and labor, including those employed in their own enterprise, are free to work, family members, casual workers and interstate workers. They include not only employees, but also those who do not work temporarily. In addition, such studies are the only source of employment that allows unemployed and economically inexperienced people to measure together and exclude each other. The need to use these indicators in the analysis of labor market indicators is one of the most important requirements for international standards.

The household survey is a separate household or business self-employment, which makes it possible to compare the data of such studies with individual, family and other demographic and socioeconomic characteristics of households. These resources are often more limited than other sources of information.

By defining changes within and between labor force categories, household surveys can be organized for not only a specific period or a specific date, but also to reflect dynamics.

Given the fact that in many countries, such as the economically active population, enterprises and administrative documents, virtually no other source of information or more or less complete, the development of household survey programs can be the most urgent and relatively easier task. However, it should be noted that data collection based on such studies may have some negative consequences in terms of value, quality, the capabilities of some small regions and groups, etc. 
In Western countries, selective surveillance studies are the most common, and they are regularly monitored, so they can be considered as one type of report. Depending on the range of studies conducted during the study, different types of selection will be used. Usually the size of the contest is $2-5 \%$, and the contest itself is organized in such a way as to avoid submission errors. For international comparisons, measuring the unemployment rate should be considered in the context of the study of labor. It was found that household surveys are more suitable for measuring the unemployment rate in accordance with international standards than other sources, although international standards in the area of unemployment statistics are determined for their use regardless of sources of information (household surveys, health insurance reports, employment centers). Nevertheless, in most developed countries and some developing countries, reports from insurance agencies and unemployment centers are used as a cheap source of current information on unemployment. Given the extremely large number of routine observations in administrative institutions, some countries are used to analyze data and the dynamics of unemployment in small regions. However, these types of official registration cannot serve as the main source of information for international comparisons. In many countries (especially in developing countries), insurance and employment centers do not function properly and do not have full coverage, often their reports are limited to certain categories and certain categories of the population. Moreover, given the fact that these data vary from country to country and from time to time, due to legal and administrative regulations, as well as differences in national differences and definitions, administrative resources are insufficient for international standards and comparisons. In defining the international labor market, there is a need for statistical information on the migration and migration of migrant workers and the population in terms of assessing the extent to which workers from the same states move to the domestic market of other countries.

\section{Analysis}

Legitimate statistics help assess the effectiveness of government decisions about migration, their consequences and outcomes, and compare migration flows in different parts of the world.

Since the problems of accounting for migration and the theory of migration movements were not sufficiently developed, accounting for migration was one of the most complex types of accounts. As for the international registration of labor migration, there are more problems.

Although there are problems with studying international migration and comparing statistical data, including an attempt to unify its indicators in 1901, there are still no ideas in the definition of "immigrants" and "immigrants". For example, in Germany, "persons crossing the border with the intention of residing in the country" are considered immigrants, in Japan - "citizens and foreigners coming from abroad", "passengers entering the state" in Yemen, in Russia - by working persons or students (Less than 1,5 months of training is exception), and their followers are called "immigrants". There are also problems in differentiation between long-term migration and relatively shortterm migration. For example, in the United States, there is no difference between permanent and temporary migration; only immigrants who come to the state for permanent residence are considered immigrants, and all the rest are included in the category of nonimmigrant.

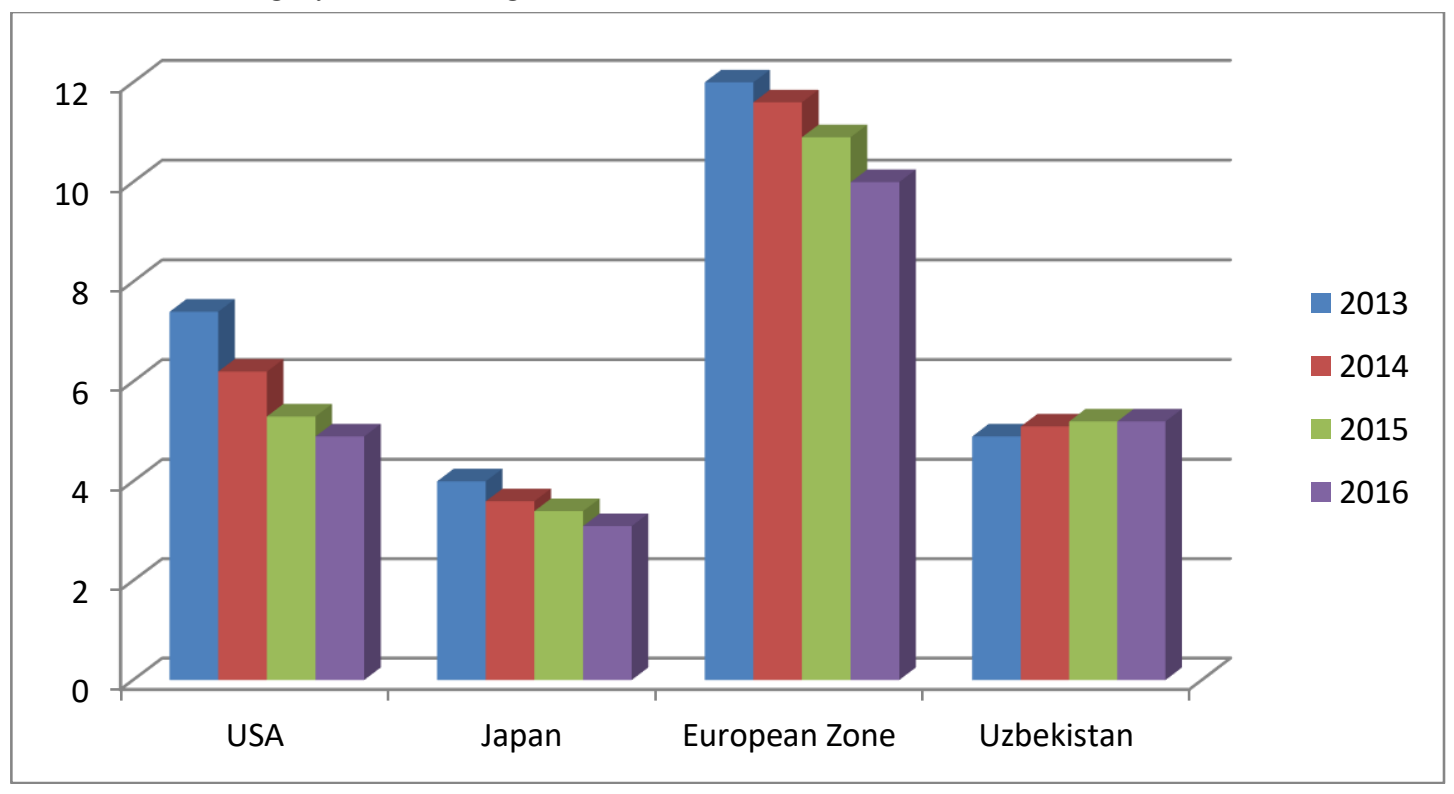

Figure 1. Unemployment Rates in 2013-2016 in Uzbekistan and Developed Countries Source : International Financial Statistics , 2010 
Even in some progress places, some legal documents may hamper its further development. For example ILO has developed international statistics widely used definition of the term "hard-working immigrants" maximize "the state is not at the expense of their journey to another country to work for migration, and also to work as an immigrant in accordance with the law a person can be allowed to any person Includes "This definition can be used to standardize statistical indicators for migration, but according to ILO Conventions №-97 (1949) and №-143 (1975), seasonal labor migrants and frontal workers are not included in the spheres of course, creates inconvenience in statistical calculations and creates a basis for discrimination against migrant workers. At the European Demographic Conference in Strasbourg (September 1966), much attention was paid to international migration, and many states are more interested in reporting on re-employment than on those who leave the country. For example, in France, statistics only take into account the arrival of migrant workers and members of their families, but only those who originally came from Algeria and return home are considered immigrants. In Belgium and the Netherlands every year, strict control of the number of labor migrants, but the total number of foreign workers per day (except for the dates of registration of the population) is not possible. Foreigners who emigrate from Saudi Arabia are considered immigrants. In the United States, these people are usually not identified, but tens of thousands of people leave the country every year. Differences can be significant compared to data from the same case, obtained from different countries. For example, in 1910-1913 315230 passports were issued for Hungarians passports, while European ports statistics spread abroad and 433230 Hungarians were registered in other countries.

The current number of migrants in Russia is registered in the Ministry of the Interior Affairs, which indicates the population at the place of residence. At present, statistical observations are being conducted over the status of residence for more than 1.5 months. The goals of migration are based on the tasks of migration - a new place of residence, work, business trip, etc. People who visit or leave the yard in summer courtyards outside the statistical register; persons leaving for resorts, sanatoriums, rest homes and other recreational facilities for rest and treatment; for the treatment of hospitals and other medical and preventive facilities; on holidays; persons who studied or traveled for up to 1.5 months; Participation in conventions, conventions and meetings. In addition, excursions, tourists and persons in the same administrative district were not registered in the same settlement, except for those who moved to rural settlements or those who lived in the same settlement (except for movement around the city).Calculations of migration were carried out based on statistical reports on arrival and departure, specially designed for statistical processing in statistical offices. These bullets are produced by the Ministry of Internal Affairs of the Ministry of Internal Affairs of Russia, as well as address and exit leaflets used to address information.

Children under 16 who came or went with adults is not issued a permit. Information about them (name, sex, date of birth and month) was written on one of the parcels of parents to avoid recall.

From 1996 preparatory work for the transition to new system of citizens registration will be carried out and the provisions of the Law of Russian Federation "On freedom of movement, citizenship and freedom of living for Russian citizens in the Russian Federation", as well as rules of staying and expulsion from Russian citizenship in the territory according to guideline of statistical registration card for migrant workers. The transition to a new system for collection and development of migrant records began in 1997. Another source of information for visitors from abroad or outside of former USSR.

There are data on the passport and visa regime of the Ministry of Internal Affairs of Russia: for arrivals - the number of persons who have a permanent residence permit; for those who leave the country for permanent residence, including foreigners and stateless persons residing in Russia. Obtaining permits to leave do not indicate that they will be issued actually this year.

Thus, there are two sources of information on migration between Russia and other countries- PVS data and permits with statistic accounts. Data from these sources can now be closer to each other and shared.

Migrant workers recognized as refugees or internally displaced persons in Russian Federation are registered by Federal Migration Service of Russia upon registration of these persons.

The calculation of migration is sometimes carried out during the census and special surveys. For example, the question of survival was included in the 1970,1979 and 1989 census. The 1989 census program also included the question of the place of birth, for those who did not live in this settlement since the birth: from where they came from the city or the village - where they live.

In the future registration of the population of the Republic of Uzbekistan, taking into account the above experience, we propose to include the following questions in the questionnaires for describing external labor migration: Have you worked on an ongoing basis outside the Republic of Uzbekistan (yes, no), and if yes, indicate that: type and characteristics , average salary; If you work outside the Republic of Uzbekistan, how quickly you return home (once a week, once a week, once a week, once a month, once a quarter, once a year).

Information obtained based on responses to the proposed responses can be combined with the socio-demographic characteristics of migrants, and not only to determine a better and quantitative assessment of labor migration, but also to determine the type of migrant. 
Specific sample surveys of population migration include the study of migration and post-migration conditions of migrants, their demographic and social characteristics. Selection Surveillance survey can also contain information on possible migration, asking questions about the purpose of resettlement.

In the context of internationally-integrated use of the labor force, it will be important to select labor migration from Uzbekistan to the CIS and far-abroad countries. An understanding of the financial aspects of the problem can be characterized by conducting household surveys in the context of selective surveillance studies or in labor force surveys.

The lack of detailed migration statistics in Uzbekistan has a profound impact on the analysis and assessment of our country's participation in the international exchange of labor. Statistics of Uzbekistan, based on official reports, cover only a very small part of the current migration flows. One way to expand the database on migration flows can be to attract customs statistics for individuals, since each person passing through the state border fills in a customs declaration. The information contained therein has a number of criteria for the analysis of migration flows, that is, when citizens leave, their departure time and direction, their distribution through state border crossings, etc. Customs statistics cannot be used to solve immigration problems. Today, Uzbekistan is seen as a transit route to some western immigrants by some illegal immigrants. They pose a serious threat to the economic security of Uzbekistan, as they often become state drug dealers, smugglers, carriers and suppliers of precious stones and metals.

Secret aspects and assessments remain beyond government control, so you can only think about illegal immigration. It would be possible to make these calculations if all reporting states used at least one or all statistical accounts simultaneously. But, as a rule, in most countries only one method is used. For example, in 1936-47 the distribution of migration measures in different countries was as follows: a) port statistics - Great Britain, Italy, Spain, Portugal; (b) Border statistics - USA, Italy, Canada, New Zealand, Chile, Colombia, Northern Rhodesia; c) Ticket registration - Italy, Mexico; (g) Transportation of transport contracts - Luxembourg, Norway; (d) Passport statistics - in the Philippines and the Maltese Islands; (e) Population registration statistics - in Belgium, Luxembourg, Switzerland and Sweden.

The main sources of information on the number, content and directions of international migration flows of migrant workers are:

- Border control statistics (police or immigration authorities that monitor entry and exit controls) is the most common way of obtaining information that identifies data at a given time;

- Statistics of population registrars (information on foreign passports, entry visas, etc.);

- Passport statistics for citizens of this state;

- Various surveys, resettlement applications and population registration statistics - this resource allows you to study international migration for a certain period of time, that is, to study the dynamics of the phenomenon whose source is most accurate;

- On the basis of sea and air ports, declarations of shipbuilding or other administrative documents of navigation companies or on the basis of individual leaflets received by each commander or head of the family;

- Permits statistics, immigration agreements, etc. for the employment of their citizens abroad or for the hiring of foreign labor.

As a result, data on the possibilities of territorial migration are distributed directly and indirectly.

Direct methods for calculating migration consist of a list of DC currents of each individual migration.

Indirect methods for calculating migration are often carried out in the form of an assessment and are based on sampling observational data, labor statistics and traffic statistics that cannot be directly replaced by a detailed description of the situation. Their sharing can help to analyze the population and labor migration by helping to expand more precisely and comprehensively take into account migration processes in the description of the international labor market.

\section{References}

- Abdurahmonov Q. X. Labor economics. Tashkent. “MEHNAT”, 2009.

- Reznik G. A., Maskayeva A.I. Mobility as a factor of the development of labor market. Penza. - 2006.

- Umarova M. A. PhD dissertation on theme " The issues of economic-statistical analysisof the labor market of the Republic of Uzbekistan” Tashkent 2010.

- Yudina T. N. Migration: glossary of main terms : Academic Project 2007 